\title{
A Cost-Effective Air Quality Supervision Solution for Enhanced Living Environments through the Internet of Things
}

\author{
Gonçalo Marques (D) and Rui Pitarma* \\ Unit for Inland Development, Polytechnic Institute of Guarda, Avenida Doutor Francisco Sá Carneiro $\mathrm{N}^{\circ} 50$, \\ 6300-559 Guarda, Portugal; goncalosantosmarques@gmail.com \\ * Correspondence: rpitarma@ipg.pt; Tel.: +351-2712-20111
}

Received: 31 December 2018; Accepted: 30 January 2019; Published: 1 February 2019

check for updates

\begin{abstract}
We spend about $90 \%$ of our lives in indoor living environments. Thus, it is essential to provide indoor air quality monitoring for enhanced living environments. Advances in networking, sensors, and embedded devices have made monitoring and supply of assistance possible to people in their homes. Technological advancements have made possible the building of smart devices with significant capabilities for sensing and connecting, but also provide several improvements in ambient assisted living system architectures. Indoor air quality assumes an important role in building productive and healthy indoor environments. In this paper, the authors present an Internet of Things system for real-time indoor air quality monitoring named iAir. This system is composed by an ESP8266 as the communication and processing unit and a MICS-6814 sensor as the sensing unit. The MICS-6814 is a metal oxide semiconductor sensor capable of detecting several gases such as carbon monoxide, nitrogen dioxide, ethanol, methane, and propane. The iAir system also provides a smartphone application for data consulting and real-time notifications. Compared to other solutions, the iAir system is based on open-source technologies and operates as a totally Wi-Fi system, with several advantages such as its modularity, scalability, low cost, and easy installation. The results obtained are very promising, representing a meaningful contribution for enhanced living environments as iAir provides real-time monitoring for enhanced ambient assisted living and occupational health.
\end{abstract}

Keywords: ambient assisted living (AAL); enhanced living environments; health monitoring; indoor air quality (IAQ); IoT (Internet of Things); occupational health; smart cities

\section{Introduction}

In $2050,20 \%$ of the total population will be aged 60 years or older [1]; consequently, the expansion of disorders, medical services costs, and lack of caregivers will lead to significant social impact. Therefore, ambient assisted living (AAL) is a relevant field of research. The AAL innovations are intended to address the challenge of ageing populations to keep their independence as long as possible. Actually, 87\% of individuals prefer to remain in their homes and bear the significant cost of nursing care [2].

On one hand, continuous technological advances have made possible the building of smart devices with significant capabilities for sensing and connecting to provide several advancements in AAL system architectures [3-5]. In particular, the advances in networking, sensors, and embedded systems enable real-time monitoring for enhanced living environments and healthcare [6]. On the other hand, there is a vast array of challenges in the design and implementation of an effective AAL system, such as information architecture, interaction design, human-computer interaction, ergonomics, 
usefulness, and accessibility [7]. There are also social and ethical issues, such as the acceptance by the older adults and the privacy and confidentiality that should be a requisite of AAL solutions. It is imperative to ensure that technology does not replace human care and should be used as an essential complement.

Internet of Things (IoT) is a paradigm where objects are connected to the internet and support sense capabilities. The pervasive presence of a variety of things or objects that can be accessed through unique addressing schemes with interaction and cooperation features is the base of the IoT concept [8]. IoT has significant influence on smart manufacturing, providing optimization and automation to administration processes such as entry and exit registration. On one hand, the IoT can be used to provide product trackability in the manufacturing process, allowing it to be managed remotely, leading to cost reductions. On the other hand, the IoT presents an important role in process automation and predictive analytics, delivered by the incorporation of artificial intelligence algorithms for enhanced performance [9].

Tendentiously, IoT devices should be ubiquitous, context-aware, and enable ambient intelligence features closely related to AAL [10]. IoT hardware is related to radio-frequency identification (RFID), near field communication (NFC), and sensor networks at the hardware level, working with standards and protocols to support machine-to-machine communication such as those envisioned for the semantic web.

IoT holds the promise of improving people's lives through both automation and augmentation at low cost [11]. However, several challenges are related to the IoT and AAL, such as security, privacy, and legal questions [12-14]. As IoT devices are typically wireless and exposed to a public range, the ownership of data collected from IoT devices must be established [15]. A significant mobile edge computing framework to provide continuous computing services for the IoT using unmanned aerial vehicles (UAV) was proposed by the authors of [16].

Indoor air quality (IAQ) assumes an important role as far as personal exposure to pollutants is concerned because several groups of people, such as the retired, students in classrooms, and disabled persons, could stay most of their time in indoor environments. Thus, IAQ supervision is a significant method for enhanced living environments and occupational health [17].

The legislation and inspection mechanisms should be adapted to act in real time to improve global health in living environments by developing enhanced regulations for the construction and monitoring of buildings.

Simple interventions provided by homeowners and real-time monitoring produce substantial positive impacts on the IAQ [18]. Therefore, it is essential to monitor the IAQ in real time to detect unhealthy situations and plan interventions in the building for enhanced occupation health.

However, IAQ assurance using electrical devices is highly energy-expensive. Therefore, a smart IoT platform to analyze electricity consumption of air conditioners with a deep belief network algorithm was presented by the authors of [19]. Using IAQ supervision and smart meters for energy analysis, the air conditioner usage practices can be optimized to improve energy efficiency.

This paper presents the iAir system, an IAQ monitoring solution based on the IoT composed of a hardware prototype for environment sensing and web/smartphone interface for data access. This system uses an open-source ESP8266 as the processing and communication unit and a MICS-6814 air sensor as a sensing unit. The data collected is uploaded to ThingSpeak, an open-source IoT application which provides an application programming interface (API) to store and retrieve data in the cloud. On the one hand, this data can be accessed by the building supervisor to detect unhealthy conditions in real time and plan interventions to provide a more productive and healthier living environment for the occupants and be used as a decision-making tool. On the other hand, this data can be accessed by doctors to support diagnoses and to correlate patients' symptoms and health problems with the environment where they live.

Until now, several projects that aim at the creation of IAQ real-time monitoring solutions have been reported in the literature. Several IoT architectures for IAQ monitoring that incorporate open-source 
technologies for processing and data transmission and microsensors for data acquisition, but also allow access to data collected from different places simultaneously using mobile computing have been proposed by various groups [20-29]. In particular, an IAQ system based on an IoT paradigm that incorporates in its construction an Arduino, ESP8266, and XBee technologies for processing and data transmission and microsensors for data acquisition to be accessed by doctors, aiming to support medical diagnostics, is proposed by the authors of [30].

The rest of this paper is structured as follows: Section 2 presents health effects of the monitored pollutants, and Section 3 is concerned with the methods and materials used in the implementation of the sensor system; Section 4 demonstrates the system operation and experimental results, and the conclusion is presented in Section 5.

\section{IAQ Monitored Pollution Sources and their Effects on Health}

The iAir system is capable of collecting sensor data about several air quality parameters, such as $\mathrm{NH}_{3}$ (ammonia), $\mathrm{CO}$ (carbon monoxide), $\mathrm{NO}_{2}$ (nitrogen dioxide), $\mathrm{C}_{3} \mathrm{H}_{8}$ (propane), $\mathrm{C}_{4} \mathrm{H}_{10}$ (butane), $\mathrm{CH}_{4}$ (methane), $\mathrm{H}_{2}$ (hydrogen), and $\mathrm{C}_{2} \mathrm{H}_{5} \mathrm{OH}$ (ethanol). Controlling the concentrations of these gases is extremely important to provide healthy living environments. In this section, the negative effects of the monitored pollutants are described to justify the necessity to supervise these parameters.

Ammonia has different sources, such as the inhabitants and their activities, tobacco smoke, detergents containing ammonia, paints, interior drainage pipes, indoor decoration materials, and concrete admixtures [31,32]. It is a major gaseous compound with a highly hydrophilic base in the air of livestock buildings, and it is capable of reducing daily weight gain and feed utilization [33]. In northern Europe, there has been concern about indoor ammonia and possible health effects, as ammonia exposure problems are referred to in the literature [34-36]. Ammonia is also considered as the main variable for determining air quality and a significant contributor to health and equipment deterioration [37-39].

$\mathrm{CO}$ is an odorless, tasteless, and nonirritating gas formed by hydrocarbon combustion. The atmospheric concentration of $\mathrm{CO}$ is typically below $0.001 \%$, but it may be much higher in indoor environments [40]. CO poisoning is usual, potentially fatal, and probably underdiagnosed because of its nonspecific clinical presentation [41]. In Britain, between 40 and 50 deaths from $\mathrm{CO}$ poisoning are reported per year by the National Health Service [42], and in the US (United States), the same results in more than 50,000 emergency department visits per year [43]. Therefore, it is important to install automatic systems for real-time detection of $\mathrm{CO}$ poisoning for enhanced occupational health [44].

$\mathrm{NO}_{2}$ is a result of combustion that has become documented as a significant component of IAQ [45]. On one hand, short-term $\mathrm{NO}_{2}$ exposure in indoor environments followed several hours later by allergen inhalation enhances allergen-induced late asthmatic reaction $[46,47]$. On the other hand, $\mathrm{NO}_{2}$ exposure causes increased airway responsiveness in healthy and asthmatic subjects, but exercise during exposure may modify this response in asthmatics [48]. Exposure to indoor $\mathrm{NO}_{2}$ is also associated with respiratory symptoms among children with asthma in multifamily housing [49-51]. There is consistent evidence of a relationship between $\mathrm{NO}_{2}$, as a proxy for traffic-sourced air pollution exposure, with lung cancer [52]. So, it is essential to provide $\mathrm{NO}_{2}$ real-time monitoring, especially for children and asthmatic patients.

Liquid petroleum gas (LPG), also referred to as propane or butane, is a flammable mixture of hydrocarbon gases used as fuel in heating appliances, cooking equipment, and vehicles. LPG is clean, burns efficiently, is easy to use, reduces cooking time, and can significantly reduce emissions [53]. The use of LPG gas stoves negatively affects indoor volatile organic compound (VOC) levels in domestic kitchens [54]. Use of LPG cookstoves during cooking may cause the accumulation of high concentrations of pollutants, particularly in the indoor environment [55]. LPG has become more widely available with a supply infrastructure to meet demand in many countries [56]. Using IAQ real-time monitoring, these situations could be avoided and early interventions could be made in the building to provide enhanced occupational health. 
Methane differs from other VOCs in that it is mainly of biological origin. It is colorless, odorless, and nontoxic, although in very high concentrations, it can cause asphyxia by starving the air of oxygen. Methane is a short-lived greenhouse gas and ozone precursor that affects background ozone concentrations. Controlling methane emissions may be a promising means of simultaneously mitigating climate change and reducing global ozone concentrations [57]. The iAir system provides real-time monitoring of $\mathrm{CH}_{4}$ concentrations. Therefore, when the concentration exceeds healthy levels, a notification is sent to the building manager to prevent explosions with catastrophic results.

VOCs refers to organics chemicals that are present mostly as gases at room temperature. Most VOCs are at low concentrations indoors, but depending on occupant behavior, the concentrations can be are highly variable. For example, in some homes, ethanol concentrations are above $1000 \mu \mathrm{g} / \mathrm{m}^{3}$ [58]. Ethanol is present in a large variety of products used for personal care and home maintenance, such as antiseptic wipes, hand sanitizers, body lotions, perfumes, shaving products, hair care products, some pharmaceuticals, soaps, detergents, dishwashing liquids, reed diffusers, air fresheners, and floor cleaners. Proper usage and storage of these products are highly recommended to minimize exposure to ethanol and other VOCs in general. For these reasons, it is extremely important to provide real-time monitoring to identify significant problems in IAQ.

\section{Materials and Methods}

Poor IAQ represents a key factor and threat for public health problems as many people spend more than $90 \%$ of their time indoors. Several pollutants such as tobacco smoke, radon decay products, carbon monoxide, nitrogen dioxide, formaldehyde, asbestos fibers, microorganisms, and aeroallergens are intimately related to health problems [59]. Temperature and humidity monitoring are part of daily life, but in the overwhelming majority of buildings, real-time air quality monitoring is not performed. With the goal of creating a real-time, low-cost, and easy-to-install air quality monitoring solution, the $i$ Air system was developed by the authors.

The iAir system is an IAQ monitoring solution that is capable of measuring these pollutants in real-time as well as providing real-time alerts of the excessive concentration of these gases.

This system is an entirely wireless solution developed using the ESP8266 module, which implements the IEEE $802.11 \mathrm{~b} / \mathrm{g} / \mathrm{n}$ networking protocol, a family of specifications developed by the IEEE for WLANs. The IEEE 802.11 standard supports radio transmission within the $2.4 \mathrm{GHz}$ band.

The data collected from the indoor living environment are stored in a ThingSpeak platform. This IoT application enables one to aggregate, visualize and analyze live data streams in the cloud.

For data consulting, this solution uses a web page provided by the ThingSpeak platform and a mobile phone application developed in Swift for the iOS operating system (Figure 1).

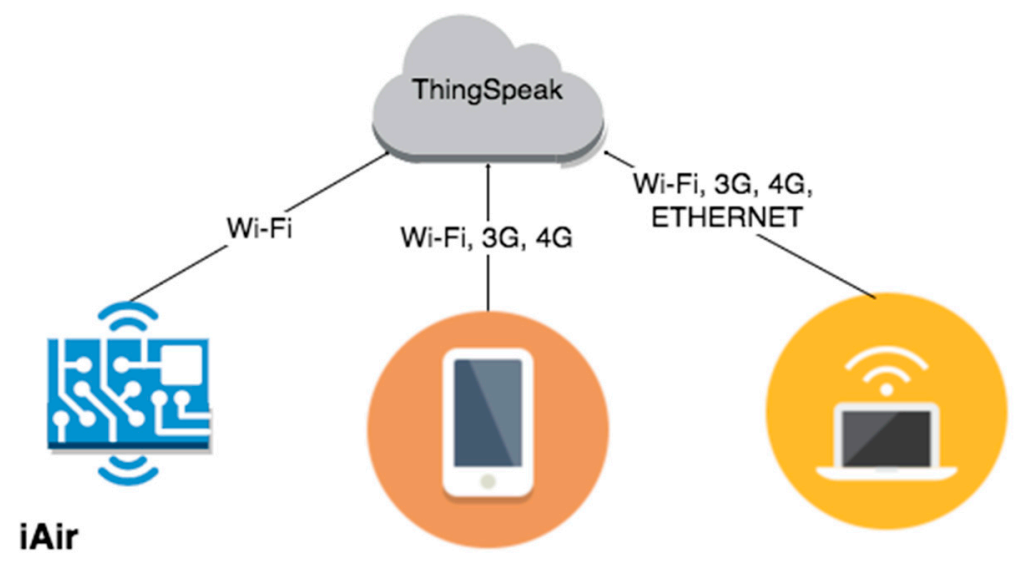

Figure 1. iAir system architecture. 
Providing a history of pollutant concentration in real-time helps in the building manager analysis concerning the precise and detailed information about the health of the living environment, as well as in planning interventions to improve IAQ.

The $i$ Air can be divided into two parts: a processing and communication unit and a sensing unit. This system is built using the ESP8266 as a microcontroller and using the built-in Wi-Fi communication feature for internet connection. The sensing unit incorporates a MICS-6814 sensor that is capable of measuring several pollutants.

Table 1 represents the air quality gases monitored by the $i$ Air solution and the resolution range. The typical accuracy for the MICS-6814 is $\pm 15-25 \%$ [60]. The sensor sensitivity varies according to the gas measured: $0.05 \mathrm{ppm}\left(\mathrm{NO}_{2}\right), 1 \mathrm{ppm}\left(\mathrm{CO}, \mathrm{H}_{2}\right.$, and $\left.\mathrm{NH}_{3}\right), 10 \mathrm{ppm}\left(\mathrm{C}_{2} \mathrm{H}_{6} \mathrm{OH}\right)$, and $1000 \mathrm{ppm}$ $\left(\mathrm{CH}_{4}, \mathrm{C}_{3} \mathrm{H}_{8}\right.$, and $\left.\mathrm{C}_{4} \mathrm{H}_{10}\right)$. This sensor was selected based on its ability to monitor various gases and having low cost. It is, however, usually recognized that the lower the price, the lower the accuracy. Nevertheless, in most applications, a qualitative assessment is sufficient to provide healthy environments and promote occupational health. So, it is perfectly suited to inspect the qualitative historical evolution of the contaminants to detect unhealthy cases.

Table 1. Gases monitored by the iAir system.

\begin{tabular}{cc}
\hline Air Pollutant & Range \\
\hline Carbon monoxide $(\mathrm{CO})$ & $1-1000 \mathrm{ppm}$ \\
Nitrogen dioxide $\left(\mathrm{NO}_{2}\right)$ & $0.05-10 \mathrm{ppm}$ \\
Ethanol $\left(\mathrm{C}_{2} \mathrm{H}_{6} \mathrm{OH}\right)$ & $10-500 \mathrm{ppm}$ \\
Hydrogen $\left(\mathrm{H}_{2}\right)$ & $1-1000 \mathrm{ppm}$ \\
Ammonia $\left(\mathrm{NH}_{3}\right)$ & $1-500 \mathrm{ppm}$ \\
Methane $\left(\mathrm{CH}_{4}\right)$ & $>1000 \mathrm{ppm}$ \\
Propane $\left(\mathrm{C}_{3} \mathrm{H}_{8}\right)$ & $>1000 \mathrm{ppm}$ \\
Isobutane $\left(\mathrm{C}_{4} \mathrm{H}_{10}\right)$ & $>1000 \mathrm{ppm}$ \\
\hline
\end{tabular}

Figure 2 represents the iAir case prototype developed in the Sketchup software and printed using a 3D printer. A brief description of the used components is presented below.

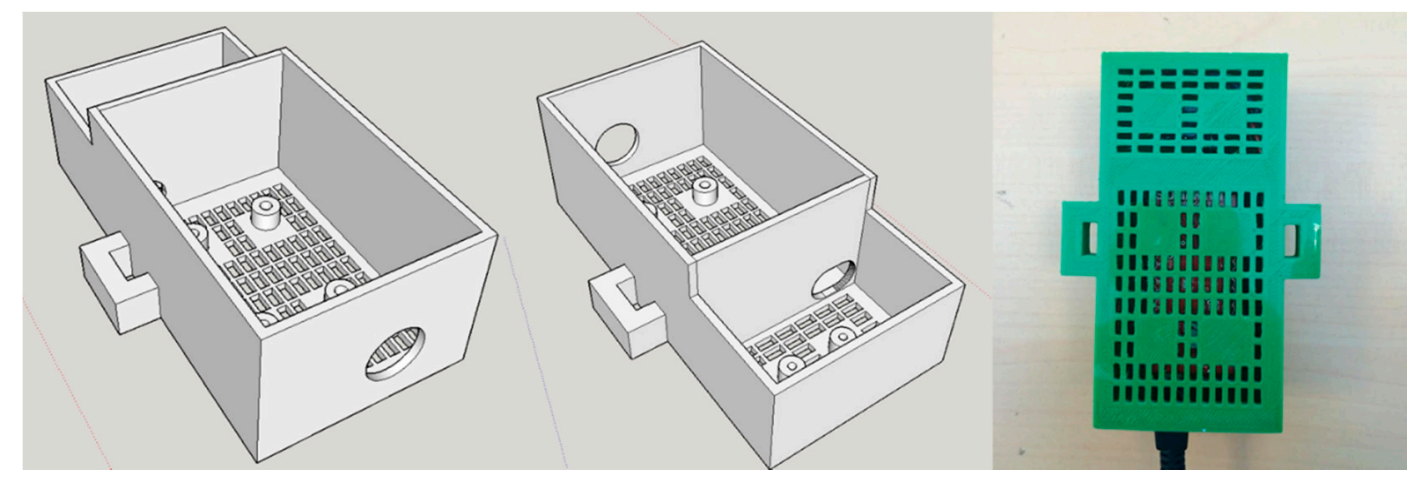

Figure 2. iAir prototype.

ESP8266 is a Wi-Fi chip with integrated antenna switches, RF balun, power amplifier, low noise amplifier, filters, and power management modules. It supports $802.11 \mathrm{~b} / \mathrm{g} / \mathrm{n}$ protocols, $2.4 \mathrm{GHz}$ $\mathrm{Wi}-\mathrm{Fi}$, and WPA/WPA2, has an integrated low-power 32-bit MCU, an integrated 10-bit ADC, has a standby power consumption of $<1.0 \mathrm{~mW}$ (DTIM3), and can operate in the temperature range of approx. $-40{ }^{\circ} \mathrm{C}-125{ }^{\circ} \mathrm{C}[61]$.

MICS-6814 is a compact metal oxide semiconductor (MOS) sensor with three fully independent sensing elements in one package. It is a robust and energy efficiency sensor. The $i$ Air incorporates an I2C Groove Multichannel Gas Sensor that supports three fully independent sensing elements in one 
package. It is built with an ATmega168PA and provides a I2C interface with a programmable address. It also allows disabling the heating functionality for low power.

The firmware of the iAir is implemented using the Arduino Core that is an open-source platform that aims to enable the use of common Arduino functions and libraries directly on the ESP8266 MCU (microcontroller unit) without an external microcontroller.

The data collected is transferred to a ThingSpeak channel using HTTP, API secret key, and channel ID. ThingSpeak stores the data in a channel; each channel has up to 8 data fields, a location field, and a status field. The iAir sends the collected data every $30 \mathrm{~s}$ (Figure 3).

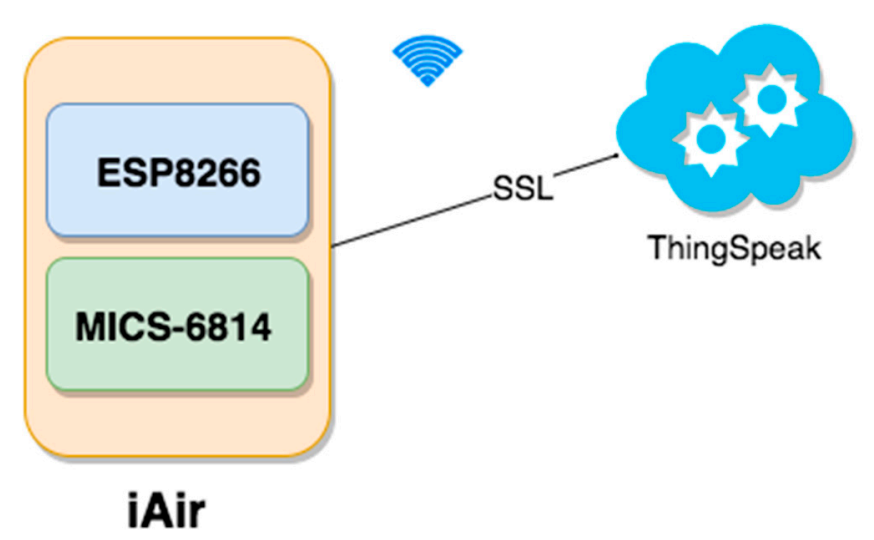

Figure 3. iAir and ThingSpeak platform communication.

The iAir is a suitable cost-effective solution for enhanced living environments, which costs an estimated 59.88 USD (Table 2).

Table 2. Cost of the iAir system.

\begin{tabular}{cc}
\hline Component & Cost \\
\hline ESP8266 & 10.39 USD \\
MICS-6814 & 39.90 USD \\
Cables and box & 9.59 USD \\
Total & 59.88 USD \\
\hline
\end{tabular}

At present, IAQ monitoring solutions for residential and/or commercial/service buildings are expensive and are based on random sampling. However, these procedures are limiting by providing only information related to a specific sampling and being devoid of spatiotemporal behavior. Some of these solutions offer portability and are compact, offering data logging on the equipment itself, but do not allow real-time data availability for building managers to enable rapid and efficient intervention to improve occupational health. The solutions available on the market are expensive and do not offer mobile compatibility for data consulting and notifications. Table 3 presents a summary of the solutions available in the market; prices were obtained from Amazon (accessed on 23 January 2019).

Table 3. Monitoring solutions available on the market.

\begin{tabular}{cccc}
\hline & Air Pollutant & Range & Price \\
\hline SMART SENSOR AR8500 & $\mathrm{NH}_{3}$ & $0-100 \mathrm{ppm}$ & $280 \mathrm{USD}$ \\
FORENSICS NR3000 & $\mathrm{NH}_{3}$ & $0-1000 \mathrm{ppm}$ & 240 USD \\
QIRUY NH3 MONITOR & $\mathrm{NH}_{3}$ & $0-100 \mathrm{ppm}$ & $170 \mathrm{USD}$ \\
BW GAXT-A-DL & $\mathrm{NH}_{3}$ & $0-100 \mathrm{ppm}$ & $490 \mathrm{USD}$ \\
SENSOR INSPECTOR PRO & $\mathrm{CO}$ & $0-2000 \mathrm{ppm}$ & $200 \mathrm{USD}$ \\
KLEIN TOOLS ET100 & $\mathrm{CO}$ & $0-1000 \mathrm{ppm}$ & $100 \mathrm{USD}$ \\
SMART SENSOR AR8900 & $\mathrm{NO}_{2}$ & $0-20 \mathrm{ppm}$ & $300 \mathrm{USD}$ \\
\hline
\end{tabular}


Most of the solutions on the market only allow a history of data limited to the device memory and require data downloading and manipulation procedures with specific software. In this way, the development of innovative environmental monitoring systems based on state-of-the-art technologies that allow real-time analysis becomes essential. Thus, the $i$ Air project aims to develop a monitoring system with integrated technology, combining sensitivity, flexibility, and accuracy of measurement in real time, allowing significant evolution of the current air quality controls. The iAir system provides easy, intuitive, and fast access to building air quality data as well as essential notifications in the case of poor ambient quality to provide real-time intervention and improve occupational health.

For test validation and research, an iOS application was developed with the Swift programming language in Xcode IDE (integrated development environment) and is compatible with iOS 7 and above [62]. Therefore, the minimum requirements to install the mobile application is an iPhone 4 or above with $512 \mathrm{MB}$ of RAM and an Apple A4 CPU. This app, named iAirMobile, has two important features, as it permits not only real-time consulting of the last data collected, but access to the history of the air quality parameters in the graphical representation and also receiving real-time notifications to advise the user of when the air quality is defective. However, the Android and Windows users can still use the web portal for data consulting. Regarding the considerable Android market quota, the authors plan to develop an Android version of the mobile application to support the notification features for those users.

\section{Results and Discussion}

The iAir system allows data consulting in terms of graphical or numerical values using the web or a smartphone interface. Samples of the data collected by the system are shown in Figures 4-6 for different air pollutants.

Figure 7 represents the experiment architecture of the iAir solution. For testing purposes, a laboratory of the Higher Education Institution in Portugal was monitored. The iAir was powered using a $5 \mathrm{~V}$ 10,000 $\mathrm{mA}$ power bank connected by a micro USB cable. The data collected shows that under defective ventilation, IAQ levels are very different from the typical values for living environments.

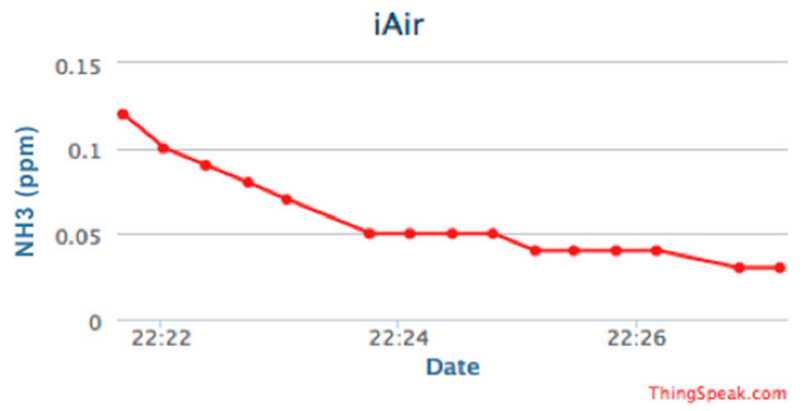

Figure 4. $\mathrm{NH}_{3}$ concentration (ppm); data obtained in the tests performed.

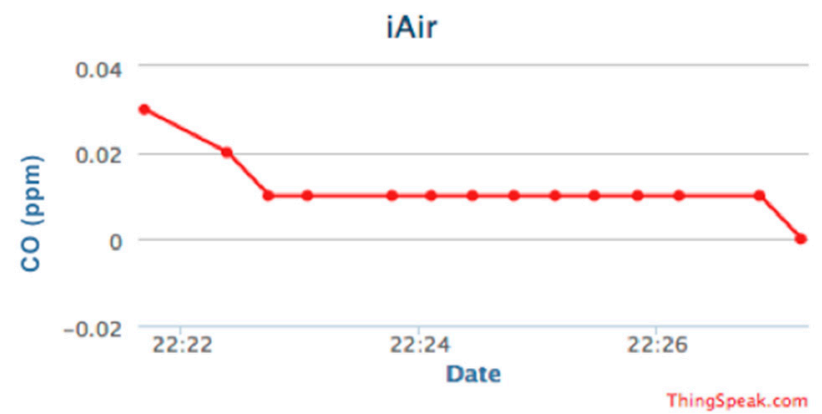

Figure 5. CO concentration (ppm); data obtained in the tests performed. 
iAir

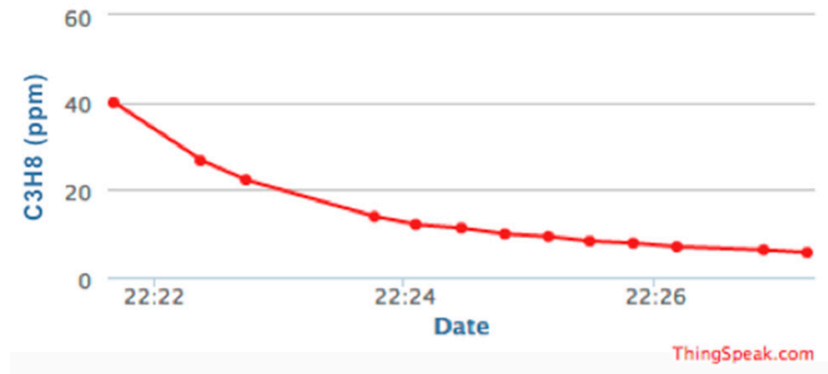

Figure 6. $\mathrm{C}_{3} \mathrm{H}_{8}$ concentration (ppm); data obtained in the tests performed.

The IAQ supervision and analysis in real-time not only can be assumed as a relevant decision-making tool to plan behaviour changes for enhanced occupational health, but also to recognise unhealthy conditions. Figure 7 represents the installation scheme.

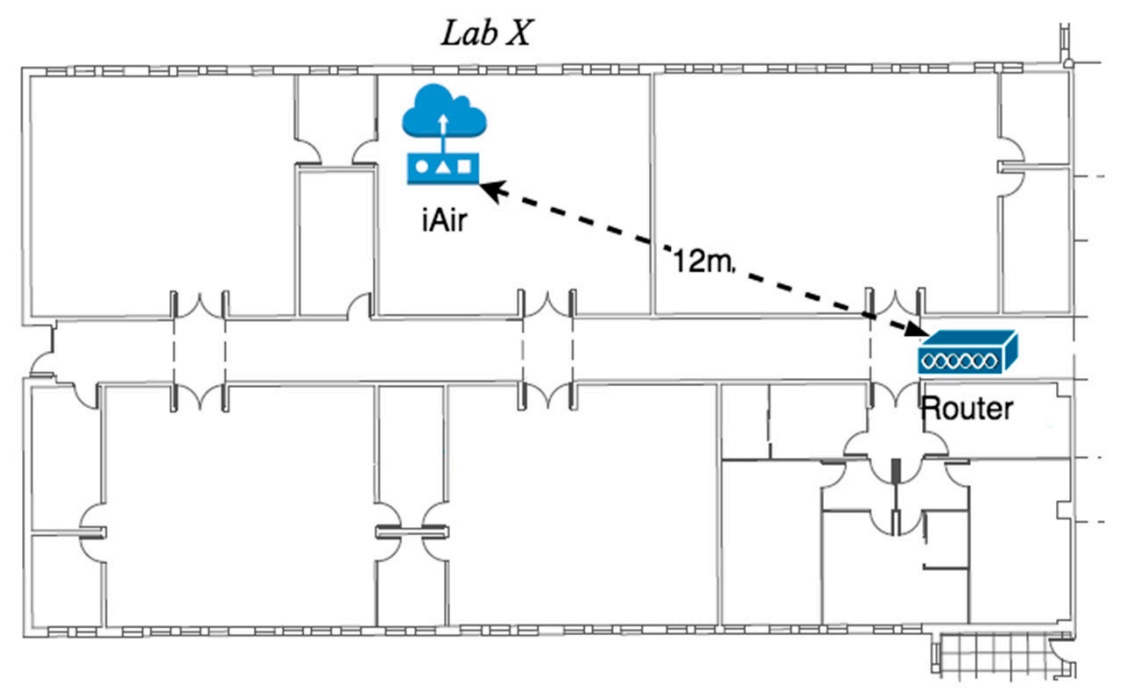

Figure 7. Installation schema.

Smartphones are an integral part of the daily routines of developed countries' individuals. The US has had exponential growth in the use of the smartphone. In fact, device ownership by adults was at $33 \%$ in $2011,56 \%$ at the end of 2013 , and $64 \%$ in early 2015 [63]. Also in the Netherlands, $70 \%$ of the total population and $90 \%$ of the adolescents own a smartphone [64]; in Germany, $40 \%$ of the people use a smartphone [65], and in the UK (United Kingdom), 51\% of adults owned smartphones [66]. Smartphones incorporate excellent processing, storage, and sensing capabilities and can be used to provide intuitive access to the monitoring data. Therefore, a smartphone application, iAirMobile, was developed by the authors to provide intuitive and real-time access to the monitored data in numerical and chart forms (Figure 8).

Table 4 presents several mobile applications for IAQ available for iOS and Android operating systems.

Compared with similar applications, the iAirMobile provides $\mathrm{NH}_{3}, \mathrm{CO}$, and $\mathrm{NO}_{2}$ supervision for enhanced occupational health. These parameters are not monitored by any application described in Table 4. However, these parameters have an important role to provide safe and healthy spaces.

The iAir solution is a multifeature tool for living environments' air quality analysis, and can support interventions to develop more productive indoor environments (Figure 8). The iAir solution has several advantages, such as modularity, small size, low-cost construction, and easy installation.

Particularly, IAQ monitoring is a trending topic for which some other low-cost and open-source monitoring systems that had been developed [67-73]. A summary of these studies is presented in Table 5. 


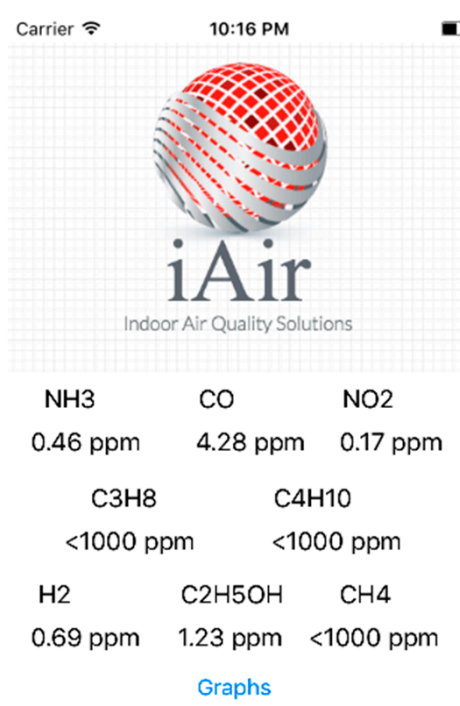

(a)

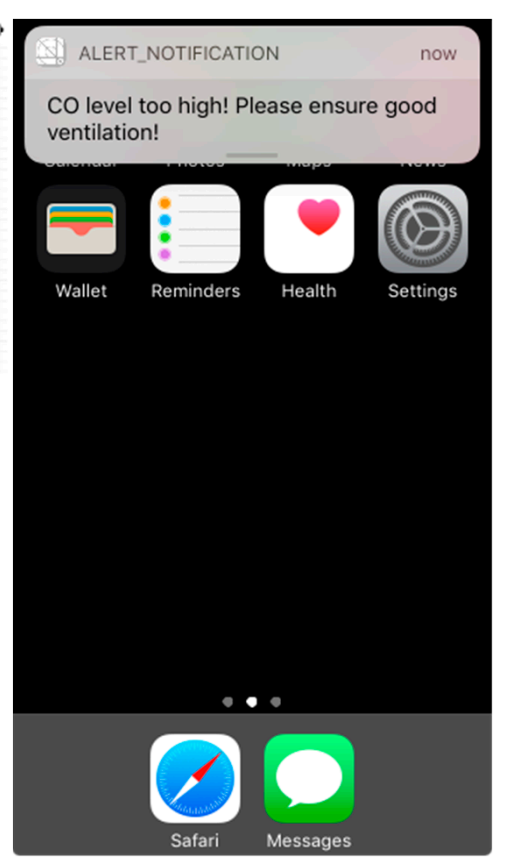

(b)

Figure 8. (a) iAirMobile last collected data; (b) example of an iAirMobile notification.

Table 4. IAQ mobile applications available on marketplaces.

\begin{tabular}{cccc}
\hline Mobile Application & Air Pollutant & Android Support & iOS Support \\
\hline Indoor Air Quality Sensor & IAQ index, temperature, $\mathrm{CO}_{2}$, & $\sqrt{ }$ & $\times$ \\
Air Mentor App & VOC, humidity & \\
Acer Air Monitor & IAQ index, temperature, $\mathrm{CO}_{2}$, & $\sqrt{ }$ & $\sqrt{ }$ \\
Air Quality Meter & VOC, relative humidity, $\mathrm{PM}$ & $\sqrt{ }$ & $\times$ \\
AQM Air Quality Monitor & Temperature, PM, VOC, relative humidity & IAQ index, PM & $\sqrt{ }$ \\
\hline
\end{tabular}

PM: particulate matter; VOC: volatile organic compound; $\sqrt{ }$ : apply; $\times$ : does not apply.

Compared to other systems proposed by the authors of $[68,69,71,72]$ based on wireless sensor networks (WSN), the IoT provides several advantages with regard to scalability and installation in indoor living environments, as is only necessary to configure the Wi-Fi internet connection and it is not required to configure the sensor nodes and coordinators. The iAir support notification features (Figure $8 \mathrm{~b}$ ) aim to provide people with timely information and provide them with the ability to react in real time to significantly improve IAQ through the ventilation or deactivation of pollutant-producing equipment. When the parameters exceed the maximum value, the user is alerted to ensure proper ventilation. This feature is not implemented in any of the several similar solutions proposed and described in Table 3.

The incorporation of the ESP8266 module leads to several benefits. On one hand, the ESP8266 is a cost-effective microcontroller which can be used for processing and communication. On the other hand, this module can be configurated to work at $160 \mathrm{MHz}$ of CPU clock speed, contrasting with the $16 \mathrm{MHz}$ of the Arduino CPU clock speed. 
Table 5. A summary of the similar types of research on IoT platforms for real-time IAQ monitoring.

\begin{tabular}{|c|c|c|c|c|c|c|c|c|c|}
\hline Authors & MCU & Sensors & Architecture & Low Cost & Open-Source & Connectivity & Data Access & $\begin{array}{c}\text { Easy } \\
\text { Installation }\end{array}$ & Notifications \\
\hline $\begin{array}{l}\text { Srivatsa and } \\
\text { Pandhare [67] }\end{array}$ & Raspberry Pi & $\mathrm{CO}_{2}$ & WSN/IoT & $\sqrt{ }$ & $\sqrt{ }$ & $\mathrm{Wi}-\mathrm{Fi}$ & Web & $x$ & $\times$ \\
\hline $\begin{array}{l}\text { Salamone } \\
\text { et al. [68] }\end{array}$ & Arduino UNO & $\mathrm{CO}_{2}$ & WSN & $\sqrt{ }$ & $\sqrt{ }$ & ZigBee & $x$ & $x$ & $x$ \\
\hline $\begin{array}{l}\text { Bhattacharya } \\
\text { et al. [69] }\end{array}$ & Waspmote & $\begin{array}{c}\mathrm{CO}, \mathrm{CO}_{2}, \mathrm{PM}, \\
\text { Temperature, Relative } \\
\text { Humidity }\end{array}$ & WSN & $x$ & $\sqrt{ }$ & ZigBee & Desktop & $x$ & $\times$ \\
\hline $\begin{array}{l}\text { Salamone } \\
\text { et al. [70] }\end{array}$ & Arduino UNO & $\begin{array}{c}\text { Temperature, Relative } \\
\text { Humidity, } \mathrm{CO}_{2} \text {, Ligth, } \\
\text { Air velocity }\end{array}$ & IoT & $\sqrt{ }$ & $\sqrt{ }$ & ZigBee/BLE & Mobile & $x$ & $\times$ \\
\hline $\begin{array}{c}\text { Wang } \\
\text { et al. [71] }\end{array}$ & Arduino & $\begin{array}{l}\text { Temperature, Relative } \\
\text { Humidity, } \mathrm{CO}_{2}\end{array}$ & WSN & $\sqrt{ }$ & $\sqrt{ }$ & ZigBee & Desktop & $x$ & $x$ \\
\hline $\begin{array}{c}\text { Liu } \\
\text { et al. [72] }\end{array}$ & TI MSP430 & $\begin{array}{l}\text { CO, Temperature, } \\
\text { Relative Humidity }\end{array}$ & WSN & $\sqrt{ }$ & $\sqrt{ }$ & ZigBee & $x$ & $x$ & $x$ \\
\hline $\begin{array}{l}\text { Kang and } \\
\text { Hwang [73] }\end{array}$ & TI MSP430 & $\begin{array}{c}\text { CO, Temperature, } \\
\text { Relative Humidity, } \\
\text { VOC, PM }\end{array}$ & IoT & $\sqrt{ }$ & $x$ & ZigBee & $x$ & $x$ & $x$ \\
\hline
\end{tabular}

MCU: microcontroller; IoT: Internet of Things; WSN: wireless sensor networks; BLE: bluetooth low energy; $\sqrt{ }$ : apply; $\times$ : does not apply. 
The iAir Wi-Fi network configuration can be done in a few steps by the end user. When the iAir cannot access any memory stored in the Wi-Fi network, the ESP8266 turns to hotspot mode. At this stage, the end user can use a mobile device with Wi-Fi support, for example, a smartphone, to connect the hotspot and configure the SSID (service set identifier) and password of the desired Wi-Fi network through which the iAir is going to connect (Figure 9).

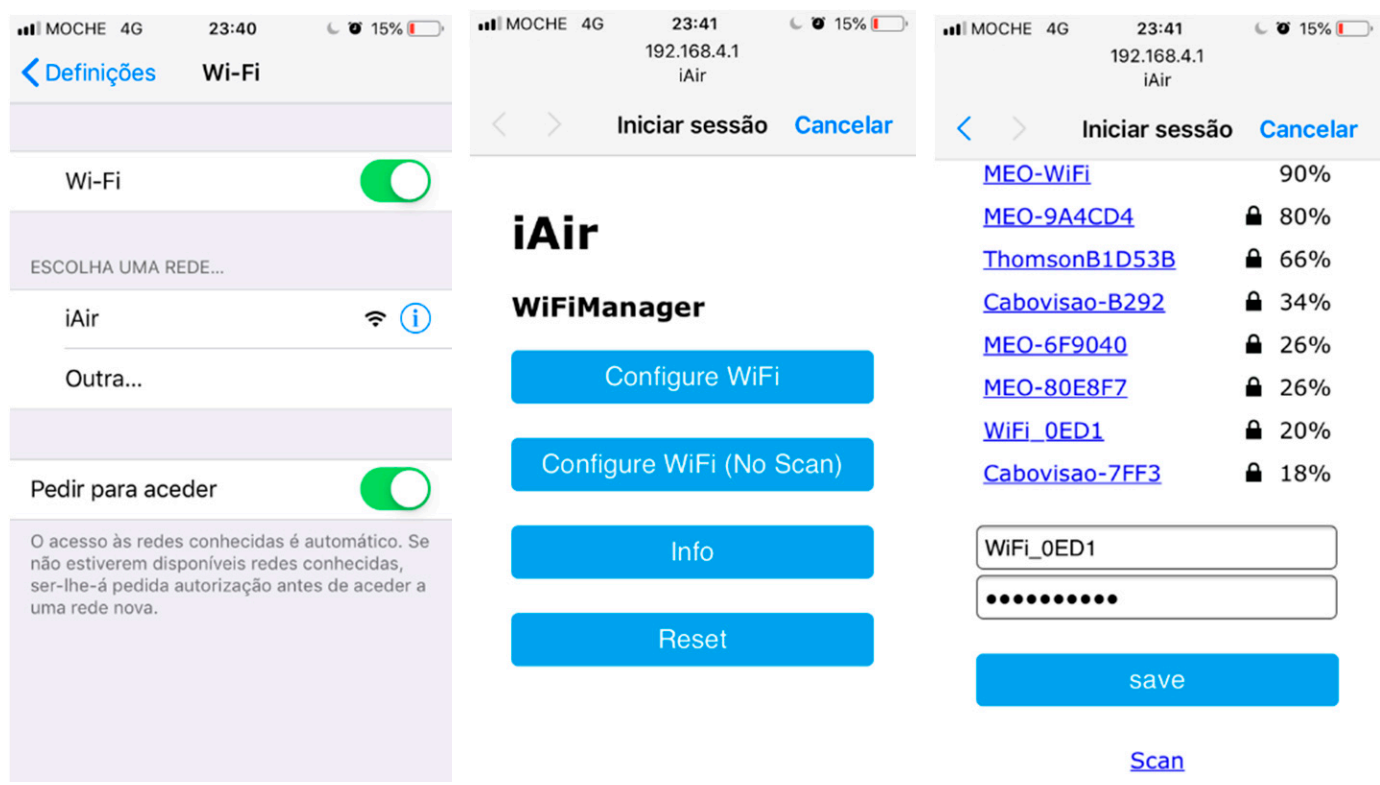

Figure 9. Wi-Fi configuration.

Compared to the majority of the state-of-the-art applications, the $i$ Air supports an easy installation process which can be done by the end user. On one hand, the easy configuration feature avoids installation costs; for the majority of similar applications, installation must be done by qualified persons. On the other hand, this feature avoids the "invasion" of privacy related to the entry of unknown persons into the home of the end user.

Another important advantage of the iAir solution is the scalability associated with the modularity of the system. An installation can start using one iAir unit and new modules can be added over time, according to the needs of the environment.

The selection of the sensor was made focusing on the cost of the system, since the main objective was to test the functional architecture of the proposed solution. Considering that the system is intended to be used in indoor environments where there is available electricity, there was no great concern with the choice of ultra-low-power sensors when focusing on the research in real-time data collection and notification functionalities.

Radon is a radioactive pollutant that affects IAQ and cannot be detected by occupants because it is odorless and invisible. This contaminant can be originated from soil or building materials. Therefore, the authors plan to incorporate a radon sensor into iAir in future work.

\section{Conclusions}

This paper has presented a complete wireless solution composed of hardware for data collection and a mobile application for data consulting and notifications. This system aims to provide real-time IAQ monitoring using IoT architecture.

Compared to other systems, iAir possess several advantages, such as low cost, open-source technologies, easy installation and configuration, and full compatibility with all residential houses as long they have internet access and the owner has a smartphone. Another significant advantage of this system is the notification system that allows users to act in real time to significantly improve IAQ through the ventilation or deactivation of pollutant-producing equipment. 
AAL and the IoT can be the key to solve the independence problems of older adults. Combined with smart homes, smartphones, wearable technology, and IoT technologies, AAL systems give many opportunities to solve problems concerning emergencies, disabilities, and diseases. In spite of AAL systems' benefits and technology advancements, human care never should be replaced, because social relations and interactions are also fundamental. IoT systems and AAL will continue side by side to mutual contribute to scientific advances in assisted living, also allowing lowering of the cost of assisted living systems. Despite all the advantages in the use of IoT architecture, many open issues such as scalability, quality of service problems, and security and privacy still exist.

The results obtained are promising, representing a significant contribution to IAQ monitoring systems based on the IoT. Nevertheless, the proposed solution has some limitations. The iAir needs further experimental validation to improve system calibration and accuracy. In addition, hardware and software improvements have also been planned to adapt the system to specific cases or problems, such as supervising laboratory environmental conditions, schoolrooms, residential homes for old people, and hospitals.

In the future, the authors aim to develop a secure information-sharing solution with health professionals to support the diagnosis of health problems. The IAQ data can be extremely useful to provide support for clinical analysis by health professionals. By monitoring IAQ, we could detect unhealthy situations in real time caused by, e.g., poor ventilation systems or inadequate intervention plans.

The iAir solution is centred on the end user, aiming to provide ubiquitous access to their living environment health.

Author Contributions: G.M. and R.P. designed the study, developed the methodology, performed the analysis, and wrote the manuscript.

Funding: This research is framed in the project "TreeM-Advanced Monitoring \& Maintenance of Trees" Nos. 023831 and 02/SAICT/2016 and was cofinanced by CENTRO 2020 and FCT, Portugal 2020, and structural funds from UE-FEDER.

Acknowledgments: The financial support from the Research Unit for Inland Development of the Polytechnic Institute of Guarda is acknowledged.

Conflicts of Interest: The authors declare no conflict of interest.

\section{References}

1. United Nations. World Population Ageing: 1950-2050; Department of Economic and Social Affairs, Population Division, United Nations: New York, NY, USA, 2002; pp. 11-13, ISBN 92-1-051092-5.

2. Centers for Disease Control and Prevention. The State of Aging and Health in America 2007. N. A. on an Aging Society; 2007. Available online: https:/ / www.cdc.gov/aging/pdf/saha_2007.pdf (accessed on 20 December 2019).

3. Manogaran, G.; Chilamkurti, N.; Hsu, C.-H. Emerging trends, issues, and challenges in Internet of Medical Things and wireless networks. Pers. Ubiquitous Comput. 2018, 22, 879-882. [CrossRef]

4. Manogaran, G.; Varatharajan, R.; Lopez, D.; Kumar, P.M.; Sundarasekar, R.; Thota, C. A new architecture of Internet of Things and big data ecosystem for secured smart healthcare monitoring and alerting system. Future Gener. Comput. Syst. 2018, 82, 375-387. [CrossRef]

5. Rathore, M.M.; Paul, A.; Ahmad, A.; Chilamkurti, N.; Hong, W.-H.; Seo, H. Real-time secure communication for Smart City in high-speed Big Data environment. Future Gener. Comput. Syst. 2018, 83, 638-652. [CrossRef]

6. Jo, D.; Kim, G.J. ARIoT: Scalable augmented reality framework for interacting with Internet of Things appliances everywhere. IEEE Trans. Consum. Electron. 2016, 62, 334-340. [CrossRef]

7. Koleva, P.; Tonchev, K.; Balabanov, G.; Manolova, A.; Poulkov, V. Challenges in designing and implementation of an effective Ambient Assisted Living system. In Proceedings of the 2015 12th International Conference on Telecommunication in Modern Satellite, Cable and Broadcasting Services (TELSIKS), Serbia, Niš, 14-17 October 2015; pp. 305-308. 
8. Atzori, L.; Iera, A.; Morabito, G. The Internet of Things: A survey. Comput. Netw. 2010, 54, $2787-2805$. [CrossRef]

9. Masse, R.A.C.; Ochoa-Zezzatti, A.; García, V.; Mejía, J.; Gonzalez, S. Saul Gonzalez Application of IoT with haptics interface in the smart manufacturing industry. Int. J. Comb. Optim. Probl. Inform. 2018, 10, 54-70.

10. Marques, G. Ambient Assisted Living and Internet of Things. In Harnessing the Internet of Everything (IoE) for Accelerated Innovation Opportunities; Cardoso, P.J.S., Monteiro, J., Semião, J., Rodrigues, J.M.F., Eds.; IGI Global: Hershey, PA, USA, 2019; pp. 100-115, ISBN 978-1-5225-7332-6.

11. Whitmore, A.; Agarwal, A.; Da Xu, L. The Internet of Things-A survey of topics and trends. Inf. Syst. Front. 2015, 17, 261-274. [CrossRef]

12. Abdel-Basset, M.; Manogaran, G.; Mohamed, M. Internet of Things (IoT) and its impact on supply chain: A framework for building smart, secure and efficient systems. Future Gener. Comput. Syst. 2018, 86, 614-628. [CrossRef]

13. Hong, S.; Kim, Y.; Kim, G.J. Developing Usable Interface for Internet of Things (IoT) Security Analysis Software. In Human Aspects of Information Security, Privacy and Trust; Tryfonas, T., Ed.; Springer International Publishing: Cham, Switzerland, 2017; Volume 10292, pp. 322-328, ISBN 978-3-319-58459-1.

14. Diro, A.A.; Chilamkurti, N. Distributed attack detection scheme using deep learning approach for Internet of Things. Future Gener. Comput. Syst. 2018, 82, 761-768. [CrossRef]

15. Hsu, C.-H. Internet of People and situated computing. Pers. Ubiquitous Comput. 2016, 20, 847-849. [CrossRef]

16. Zhou, Z.; Feng, J.; Tan, L.; He, Y.; Gong, J. An Air-Ground Integration Approach for Mobile Edge Computing in IoT. IEEE Commun. Mag. 2018, 56, 40-47. [CrossRef]

17. Walsh, P.J.; Dudney, C.S.; Copenhaver, E.D. Indoor Air Quality; CRC Press: Boca Raton, FL, USA, 1983; ISBN 0-8493-5015-8.

18. Jones, A.P. Indoor air quality and health. Atmos. Environ. 1999, 33, 4535-4564. [CrossRef]

19. Wei, S.; Ning, F.; Simon, F.; Kyungeun, C. A Deep Belief Network for Electricity Utilisation Feature Analysis of Air Conditioners Using a Smart IoT Platform. J. Inf. Process. Syst. 2018, 14, 162-175.

20. Pitarma, R.; Marques, G.; Ferreira, B.R. Monitoring Indoor Air Quality for Enhanced Occupational Health. J. Med Syst. 2017, 41, 23. [CrossRef] [PubMed]

21. Marques, G.; Pitarma, R. Health informatics for indoor air quality monitoring. In Proceedings of the 2016 11th Iberian Conference on Information Systems and Technologies (CISTI), Gran Canaria, Spain, 15-18 June 2016; AISTI: Rio Tinto, Portugal, 2016; pp. 1-6.

22. Pitarma, R.; Marques, G.; Caetano, F. Monitoring Indoor Air Quality to Improve Occupational Health. In New Advances in Information Systems and Technologies; Rocha, Á., Correia, A.M., Adeli, H., Reis, L.P., Mendonça Teixeira, M., Eds.; Springer International Publishing: Cham, Switzerland, 2016; Volume 445, pp. 13-21, ISBN 978-3-319-31306-1.

23. Marques, G.; Pitarma, R. Smartphone Application for Enhanced Indoor Health Environments. J. Inf. Syst. Eng. Manag. 2016, 4, 9.

24. Marques, G.; Pitarma, R. Monitoring Health Factors in Indoor Living Environments Using Internet of Things. In Recent Advances in Information Systems and Technologies; Rocha, Á., Correia, A.M., Adeli, H., Reis, L.P., Costanzo, S., Eds.; Springer International Publishing: Cham, Switzerland, 2017; Volume 570, pp. 785-794, ISBN 978-3-319-56537-8.

25. Marques, G.; Pitarma, R. Monitoring and control of the indoor environment. In Proceedings of the 201712 th Iberian Conference on Information Systems and Technologies (CISTI), Lisbon, Portugal, 21-24 June 2017; IEEE: Piscataway, NJ, USA, 2017; pp. 1-6.

26. Feria, F.; Salcedo Parra, O.J.; Reyes Daza, B.S. Design of an Architecture for Medical Applications in IoT. In Cooperative Design, Visualization, and Engineering; Luo, Y., Ed.; Springer International Publishing: Cham, Switzerland, 2016; Volume 9929, pp. 263-270, ISBN 978-3-319-46770-2.

27. Ray, P.P. Internet of things for smart agriculture: Technologies, practices and future direction. J. Ambient Intell. Smart Environ. 2017, 9, 395-420. [CrossRef]

28. Matz, J.R.; Wylie, S.; Kriesky, J. Participatory Air Monitoring in the Midst of Uncertainty: Residents' Experiences with the Speck Sensor. Engag. Sci. Technol. Soc. 2017, 3, 464-498. [CrossRef]

29. Demuth, D.; Nuest, D.; Bröring, A.; Pebesma, E. The AirQuality SenseBox. In Proceedings of the EGU General Assembly Conference Abstracts, Vienna, Austria, 7-12 April 2013; Volume 15. 
30. Marques, G.; Pitarma, R. An indoor monitoring system for ambient assisted living based on internet of things architecture. Int. J. Environ. Res. Public Health 2016, 13, 1152. [CrossRef]

31. Salonen, H.J.; Pasanen, A.-L.; Lappalainen, S.K.; Riuttala, H.M.; Tuomi, T.M.; Pasanen, P.O.; Bäck, B.C.; Reijula, K.E. Airborne Concentrations of Volatile Organic Compounds, Formaldehyde and Ammonia in Finnish Office Buildings with Suspected Indoor Air Problems. J. Occup. Environ. Hyg. 2009, 6, 200-209. [CrossRef]

32. Felix, E.P.; Cardoso, A.A. A method for determination of ammonia in air using oxalic acid-impregnated cellulose filters and fluorimetric detection. J. Braz. Chem. Soc. 2012, 23, 142-147. [CrossRef]

33. Mostafa, E.; Hoelscher, R.; Diekmann, B.; Ghaly, A.E.; Buescher, W. Evaluation of two indoor air pollution abatement techniques in forced-ventilation fattening pig barns. Atmos. Pollut. Res. 2017, 8, 428-438. [CrossRef]

34. Tuomainen, M.; Tuomainen, A.; Liesivuori, J.; Pasanen, A.-L. The 3-year follow-up study in a block of flats experiences in the use of the Finnish indoor climate classification. Indoor Air 2003, 13, 136-147. [CrossRef] [PubMed]

35. Lindgren, T. A case of indoor air pollution of ammonia emitted from concrete in a newly built office in Beijing. Build. Environ. 2010, 45, 596-600. [CrossRef]

36. Jarnstrom, H.; Saarela, K.; Kalliokoski, P.; Pasanen, A. Reference values for indoor air pollutant concentrations in new, residential buildings in Finland. Atmos. Environ. 2006, 40, 7178-7191. [CrossRef]

37. Bull, K.; Sutton, M. Critical loads and the relevance of ammonia to an effects-based nitrogen protocol. Atmos. Environ. 1998, 32, 565-572. [CrossRef]

38. Webb, J.; Menzi, H.; Pain, B.F.; Misselbrook, T.H.; Dämmgen, U.; Hendriks, H.; Döhler, H. Managing ammonia emissions from livestock production in Europe. Environ. Pollut. 2005, 135, 399-406. [CrossRef] [PubMed]

39. Saha, C.K.; Zhang, G.; Kai, P.; Bjerg, B. Effects of a partial pit ventilation system on indoor air quality and ammonia emission from a fattening pig room. Biosyst. Eng. 2010, 105, 279-287. [CrossRef]

40. Ernst, A.; Zibrak, J.D. Carbon Monoxide Poisoning. N. Engl. J. Med. 1998, 339, 1603-1608. [CrossRef]

41. Clardy, P.F.; Manaker, S.; Perry, H. Carbon monoxide poisoning. UpToDate. Literature review current through: Apr 2017.

42. Haines, D. Carbon monoxide poisoning. Med. -Leg. J. 2016, 84, 59. [CrossRef]

43. Weaver, L.K. Carbon Monoxide Poisoning. N. Engl. J. Med. 2009, 360, 1217-1225. [CrossRef]

44. Blumenthal, I. Carbon Monoxide Poisoning. J. R. Soc. Med. 2001, 94, 270-272. [CrossRef] [PubMed]

45. Frampton, M.W.; Morrow, P.E.; Cox, C.; Gibb, F.R.; Speers, D.M.; Utell, M.J. Effects of Nitrogen Dioxide Exposure on Pulmonary function and Airway Reactivity in Normal Humans. Am. Rev. Respir. Dis. 1991, 143, 522-527. [CrossRef] [PubMed]

46. Strand, V.; Rak, S.; Svartengren, M.; Bylin, G. Nitrogen dioxide exposure enhances asthmatic reaction to inhaled allergen in subjects with asthma. Am. J. Respir. Crit. Care Med. 1997, 155, 881-887. [CrossRef] [PubMed]

47. Mills, I.C.; Atkinson, R.W.; Kang, S.; Walton, H.; Anderson, H.R. Quantitative systematic review of the associations between short-term exposure to nitrogen dioxide and mortality and hospital admissions. BMJ Open 2015, 5, e006946. [CrossRef] [PubMed]

48. Folinsbee, L.J. Does nitrogen dioxide exposure increase airways responsiveness? Toxicol. Ind. Health 1992, 8, 273-283. [CrossRef] [PubMed]

49. Belanger, K.; Gent, J.F.; Triche, E.W.; Bracken, M.B.; Leaderer, B.P. Association of Indoor Nitrogen Dioxide Exposure with Respiratory Symptoms in Children with Asthma. Am. J. Respir. Crit. Care Med. 2006, 173, 297-303. [CrossRef] [PubMed]

50. Pilotto, L.; Douglas, R.; Attewell, R.; Wilson, S. Respiratory effects associated with indoor nitrogen dioxide exposure in children. Int. J. Epidemiol. 1997, 26, 788-796. [CrossRef]

51. Favarato, G.; Anderson, H.R.; Atkinson, R.; Fuller, G.; Mills, I.; Walton, H. Traffic-related pollution and asthma prevalence in children. Quantification of associations with nitrogen dioxide. Air Qual. Atmos. Health 2014, 7, 459-466. [CrossRef] 
52. Hamra, G.B.; Laden, F.; Cohen, A.J.; Raaschou-Nielsen, O.; Brauer, M.; Loomis, D. Lung Cancer and Exposure to Nitrogen Dioxide and Traffic: A Systematic Review and Meta-Analysis. Environ. Health Perspect. 2015, 123, 1107-1112. [CrossRef]

53. Amegah, A.K.; Jaakkola, J.J. Household air pollution and the sustainable development goals. Bull. World Health Organ. 2016, 94, 215-221. [CrossRef]

54. Lee, S.C.; Li, W.-M.; Ao, C.-H. Investigation of indoor air quality at residential homes in Hong Kong-Case study. Atmos. Environ. 2002, 36, 225-237. [CrossRef]

55. Kandpal, J.B.; Maheshwari, R.C.; Kandpal, T.C. Indoor air pollution from domestic cookstoves using coal, kerosene and LPG. Energy Convers. Manag. 1995, 36, 1067-1072. [CrossRef]

56. Cardiopulmonary Outcomes and Household Air Pollution Trial (CHAP) Trial Investigators; Fandiño-Del-Rio, M.; Goodman, D.; Kephart, J.L.; Miele, C.H.; Williams, K.N.; Moazzami, M.; Fung, E.C.; Koehler, K.; Davila-Roman, V.G.; et al. Effects of a liquefied petroleum gas stove intervention on pollutant exposure and adult cardiopulmonary outcomes (CHAP): Study protocol for a randomized controlled trial. Trials 2017, 18, 518.

57. Anenberg, S.C.; Schwartz, J.; Shindell, D.; Amann, M.; Faluvegi, G.; Klimont, Z.; Janssens-Maenhout, G.; Pozzoli, L.; Van Dingenen, R.; Vignati, E.; et al. Global Air Quality and Health Co-benefits of Mitigating Near-Term Climate Change through Methane and Black Carbon Emission Controls. Environ. Health Perspect. 2012, 120, 831-839. [CrossRef] [PubMed]

58. Logue, J.M.; McKone, T.E.; Sherman, M.H.; Singer, B.C. Hazard assessment of chemical air contaminants measured in residences: Hazard assessment of indoor air contaminants. Indoor Air 2011, 21, 92-109. [CrossRef] [PubMed]

59. Spengler, J.; Sexton, K. Indoor air pollution: A public health perspective. Science 1983, 221, 9-17. [CrossRef] [PubMed]

60. SGX Sensortech MICS-6814 Data Sheet. Available online: https://sgx.cdistore.com/datasheets/sgx/1143_ Datasheet\%20MiCS-6814\%20rev\%208.pdf (accessed on 18 January 2019).

61. Espressif Systems ESP8266EX Datasheet. 2018. Available online: https:/ / espressif.com/sites/default/files / documentation/0a-esp8266ex_datasheet_en.pdf (accessed on 23 January 2019).

62. Neuburg, M. iOS 7 Programming Fundamentals: Objective-c, xcode, and cocoa Basics; O'Reilly Media, Inc.: Sebastopol, CA, USA, 2013; ISBN 1-4919-4690-3.

63. Müller, H.; Gove, J.L.; Webb, J.S.; Cheang, A. Understanding and Comparing Smartphone and Tablet Use: Insights from a Large-Scale Diary Study. In Proceedings of the Annual Meeting of the Australian Special Interest Group for Computer Human Interaction, Parkville, Australia, 7-10 December 2015; ACM: New York, NY, USA, 2015; pp. 427-436.

64. van Deursen, A.J.A.M.; Bolle, C.L.; Hegner, S.M.; Kommers, P.A.M. Modeling habitual and addictive smartphone behavior. Comput. Hum. Behav. 2015, 45, 411-420. [CrossRef]

65. Montag, C.; Błaszkiewicz, K.; Sariyska, R.; Lachmann, B.; Andone, I.; Trendafilov, B.; Eibes, M.; Markowetz, A. Smartphone usage in the 21st century: Who is active on WhatsApp? BMC Res. Notes 2015, 8, 331. [CrossRef]

66. Pearson, C.; Hussain, Z. Smartphone Use, Addiction, Narcissism, and Personality: A Mixed Methods Investigation. Int. J. Cyber Behav. Psychol. Learn. 2015, 5, 17-32. [CrossRef]

67. Srivatsa, P.; Pandhare, A. Indoor Air Quality: IoT Solution. Available online: http://www.ijrat.org/ downloads/ncpci2016/ncpci-46.pdf (accessed on 22 December 2018).

68. Salamone, F.; Belussi, L.; Danza, L.; Galanos, T.; Ghellere, M.; Meroni, I. Design and Development of a Nearable Wireless System to Control Indoor Air Quality and Indoor Lighting Quality. Sensors 2017, 17, 1021. [CrossRef]

69. Bhattacharya, S.; Sridevi, S.; Pitchiah, R. Indoor air quality monitoring using wireless sensor network. In Proceedings of the 2012 Sixth International Conference on Sensing Technology (ICST), Kolkata, India, 18-21 December 2012; IEEE: Piscataway, NJ, USA, 2012; pp. 422-427.

70. Salamone, F.; Belussi, L.; Danza, L.; Ghellere, M.; Meroni, I. Design and Development of nEMoS, an All-in-One, Low-Cost, Web-Connected and 3D-Printed Device for Environmental Analysis. Sensors 2015, 15, 13012-13027. [CrossRef] [PubMed]

71. Wang, S.K.; Chew, S.P.; Jusoh, M.T.; Khairunissa, A.; Leong, K.Y.; Azid, A.A. WSN based indoor air quality monitoring in classrooms. In AIP Conference Proceedings; AIP Publishing: Melville, NY, USA, 2017; p. 020063. 
72. Liu, J.-H.; Chen, Y.-F.; Lin, T.-S.; Lai, D.-W.; Wen, T.-H.; Sun, C.-H.; Juang, J.-Y.; Jiang, J.-A. Developed urban air quality monitoring system based on wireless sensor networks. In Proceedings of the 2011 Fifth International Conference on Sensing Technology (ICST), Palmerston North, New Zealand, 28 November-1 December 2011; IEEE: Piscataway, NJ, USA, 2011; pp. 549-554.

73. Kang, J.; Hwang, K.-I. A Comprehensive Real-Time Indoor Air-Quality Level Indicator. Sustainability 2016, 8, 881. [CrossRef] 